\title{
QUESTÕES SOCIOAMBIENTAIS DA CIDADE DE LARANJAL DO JARI/AP: REFLEXÕES NA PERSPECTIVA DA EDUCAÇÃO POPULAR
}

\author{
SOCIAL AND ENVIRONMENTAL ISSUES OF THE OF LARANJAL DO JARI/AP \\ CITY: REFLECTIONS FROM THE PERSPECTIVE OF POPULAR EDUCATION
}

\section{Eliana do Socorro de Brito Paixão}

Doutora em Educação pela Universidade Federal de Uberlândia - UFU, Brasil.

Professora do Curso de Secretariado Executivo na UNIFAP, vinculada ao Departamento de Filosofia e Ciências Humanas, e membro do Grupo de Pesquisa Arquitetura e Urbanismo na Amazônia, cadastrado no CNPq.

E-mail: elianapaixao@unifap.br 


\section{QUESTÕES SOCIOAMBIENTAIS DA CIDADE DE LARANJAL DO JARI/AP: REFLEXÕES NA PERSPECTIVA DA EDUCAÇÃO POPULAR}

\section{RESUMO}

O objetivo deste artigo é suscitar reflexões acerca das questões socioambientais da cidade de Laranjal do Jari sob a ótica dos moradores participantes da pesquisa. Trata-se de uma cidade situada na área de fronteira, ao sul do estado do Amapá, que concentra 94,9\% da população do município, constituída por 39.942 habitantes. Morar em tal cidade significa conviver com heranças perversas induzidas pela instalação do Projeto Jari, na região, nos anos de 1970 época, a partir da qual, grande parte da população mora em palafitas sobre o rio Jari, cuja tessitura se assemelha a uma extensa favela fluvial. A cidade convive com graves questões socioambientais, as quais, historicamente, naturalizam-se à vida de seus moradores, relacionadas ao lixo, água, esgoto, moradia, dentre outros, as quais ratificam o índice de pobreza na ordem de $46,2 \%$ e se destacam em sua configuração urbana. A pesquisa foi de cunho qualitativo, realizada junto a 48 moradores da cidade, com os quais foram desenvolvidas atividades de campo inspiradas no Círculo de Cultura, de Paulo Freire. Os resultados apontaram que quando se trata de propor alterações no meio ambiente construído é fundamental convocar quem conhece a realidade em que vive.

Palavras-Chave: Configuração urbana. Questões socioambientais. Educação popular. 


\title{
SOCIAL AND ENVIRONMENTAL ISSUES OF THE OF LARANJAL DO JARI/AP CITY: REFLECTIONS FROM THE PERSPECTIVE OF POPULAR EDUCATION
}

\begin{abstract}
The objective of this paper is to raise reflections on the social and environmental issues of the city of Laranjal do Jari from the point of view of its residents who are taking part in this survey. It regards a city located in the frontier area, south of the state of Amapá, that concentrates $94,9 \%$ of the county's population, constituted by 39.942 inhabitants. Living in such city means to live with perverse heritages induced by the installation of Jari Project, in the region, in the 70's - a time from which a number of residents live in stilt houses over the waters of the Jari River, whose structure is that of a extended pluvial slum. The city lives with grave social and environmental issues, which, historically, have naturalized themselves to the life of the inhabitants, related to garbage, water, sewage, housing, among others, which ratify the poverty index in the order of $46,2 \%$ and are highlights in the urban configuration. The research was of qualitative nature, realized with 48 city residents, field experiments were developed inspired on the Culture Circle, from Paulo Freire. The results indicate that, when it is about proposing changes in the built environment, it is fundamental to summon those who know the reality in which he lives.
\end{abstract}

Keywords: Urban configuration. Social and environmental issues. Popular education. 


\section{INTRODUÇÃO}

O avanço capitalista em nível global e em diferentes culturas é moldado por um modelo hegemônico de desenvolvimento econômico, cujos motores são as cidades, as quais impulsionam a sociedade de consumo. São incursões que contribuem para a produção de espaços urbanos carentes de equipamentos públicos, condições de moradia e salubridade ambiental, sobretudo nas cidades dos países em desenvolvimento.

A política desenvolvimentista empreendida pelo Brasil, a partir da década de 1950, propunha um amplo programa de desenvolvimento que alcançasse os setores público e privado. Se de um lado essa modalidade de política dinamiza a economia, por outro produz efeitos degradantes ao ambiente vivido e submete à população às mais diversas degradações, a frequentes ocorrências de acidentes ambientais e, consequentemente, à vulnerabilidade social.

A região amazônica, ao longo de décadas, tem sido duramente alvejada por essa política com o advento dos grandes investidores internacionais. Concomitante a esse movimento também se expandem a exploração de recursos naturais e os impactos socioambientais, afetando, diretamente, grande parte da população que vive nas cidades. Dessa forma, urge a necessidade de reflexão sobre os desafios de reconfigurar a forma de pensar e agir diante das problemáticas ambientais.

No estado do Amapá, há uma situação ambígua, na qual graves questões socioambientais estão presentes, a despeito de o estado carregar o título de o mais preservado do Brasil. Tal situação é observada no município de Laranjal do Jari, cuja cidade-sede é a terceira maior do estado em contingente populacional. Sua origem coincide com a instalação do Projeto Jari na região, em 1967, para exploração de minério de caulim e de celulose em larga escala. Esse projeto atraiu intenso fluxo migratório, culminando em ocupações desordenadas e insalubridade ambiental, nas áreas de várzea urbanas, que se desdobrou na formação de uma favela fluvial de largas proporções.

As consequências são significativas e justificam o índice de pobreza da ordem de 46\% (IBGE, 2003). Em 10 anos a população do município que, de acordo com o censo de 2010, somava 39.942 habitantes (IBGE, 2010), cresceu 40\%. Em 2015, houve uma estimativa para 45.712 habitantes, sendo que $94,9 \%$ dos moradores permanecem concentrados na cidade de Laranjal do Jari. Cotejando os dados do censo de 2010 (IBGE, 2010), verificou-se que o 
crescimento é semelhante ao da população do estado do Amapá que também atingiu 40\%, superior a Roraima (39\%) e Acre (31\%) nesse período, enquanto que o Brasil cresceu 12,3\%. Para o porte da cidade é um índice muito elevado, considerando que é o maior dentre todos os estados brasileiros, sem a garantia de novos postos de geração de emprego e renda, como também de acesso à infraestrutura urbana.

As questões de vulnerabilidade disseminaram-se por toda a cidade. Na maioria das residências é possível observar variados tipos de mazelas socioambientais. Moradias muito precárias com banheiros externos, lixos sob as casas, a água é fornecida e armazenada de forma inadequada, não há esgoto sanitário, há elevado volume de resíduos sólidos, além de depósito de dejetos humanos sob as casas e entorno (Paixão, 2008). O Mapa de Pobreza e Desigualdade, configurado pelo IBGE revelou que a incidência de pobreza é da ordem de 46,20\% (IBGE, 2003). Esse índice foi ratificado pelo mesmo Instituto (2010), que identificou a renda per capita para a área urbana no valor de $\mathrm{R} \$ 282,86$ e que $40 \%$ da população economicamente ativa não possuem rendimentos formalizados.

De acordo com Tostes (2013) os municípios amapaenses revelam a face cruel dos municípios amazônicos. A falta de cumplicidade entre as esferas de governo também tem contribuído para que a qualidade de vida não decorra dos direitos à cidade enumerados por Lefebvre (1968). Em geral é incipiente a oferta de serviços urbanos e lenta a melhoria dos indicadores dos serviços de água, esgoto, moradia, entre outros.

Este artigo é parte da tese de doutorado intitulada $A$ realidade socioambiental de Laranjal do Jari/AP: soluções apontadas por moradores na perspectiva da Educação Popular, defendida em dezembro de 2013, a qual traz o quadro descrito que engendrou a seguinte questão de pesquisa: o que disseram os moradores da cidade de Laranjal do Jari, participantes da pesquisa, acera das questões socioambientais locais? Assim, o artigo visa suscitar reflexões acerca das questões socioambientais da cidade de Laranjal do Jari sob a ótica dos moradores participantes da pesquisa, por meio do caráter social da educação popular, que exige a busque de um olhar crítico sobre o ambiente vivido. Nessa perspectiva, dispensa-se à educação uma conotação política e transformadora, que prime pelo equacionamento ou minoração das questões socioambientais e interfira, sobretudo, na vida das populações que vivem nas periferias sociais.

O corpo deste artigo segue estruturado em cinco sessões: a primeira é de cunho introdutório para situar o leitor sobre a proposta ora apresentada; a segunda trata do 
referencial teórico que deu suporte epistemológico à pesquisa; a terceira descreve os caminhos metodológicos; a quarta sessão apresenta o olhar dos moradores sobre as questões socioambientais locais, as quais foram problematizadas, por meio dos pressupostos da educação popular; e a quinta aborda algumas considerações para reflexões acerca do quadro posto e dos resultados da pesquisa.

A relevância deste artigo pauta-se em suscitar reflexões acerca dos problemas socioambientais urbanos que gravitam nas cidades e impregnam-se na vida em sociedade, assim como, em mostrar que o ser humano, independente de classe social, sabe dizer o que pensa sobre seu contexto de vivência e propor alternativas de soluções para questões que implicam minorar a qualidade de vida em seu contexto de vivência.

\section{REFERENCIAL TEÓRICO}

O referencial teórico que norteou a fundamentação da pesquisa discute campos temáticos que se interconectam com as questões socioambientais urbanas e suas implicações. Todos os autores utilizados ofereceram um arcabouço importante para compreensão epistemológica e dentre eles se destacaram Castells (2000; 2005), Lefebvre (1968), Reigota (2004), Acselrad (2004); Carvalho (2008); Esteban (2007); Freire (1967; 1979; 2011); Laplantine e Trindade (2003); Loureiro e Franco (2014); Martins (2014) que tratam sobre espaço e configuração urbana; empreendimentos privados e conflitos ambientais; educação popular, Círculo de Cultura, imagem e educação ambiental.

\section{Espaço Urbano e Sua Complexidade}

A pesquisa abordou um campo complexo de ser elucidado - o espaço urbano, em face das peculiaridades que envolvem o ambiente, sobretudo em relação ao processo de ocupação e as relações sociais que se estabelecem e movem a dinâmica urbana, nas quais se entrelaçam as questões socioambientais analisadas.

Castells (2000) percebeu a complexidade do espaço urbano, entendendo que o processo de ocupação está vinculado às relações de produção e estrutura de poder na sociedade capitalista. Ao longo do tempo, a realidade segue se configurando a partir das condições " [...] materiais da existência e deve ser apreendida como um processo que se dá a 
cada momento histórico sendo por isso complexa e dinâmica, contraditória e inacabada" (Loureiro \& Franco, 2014, p.158). Segundo Castells (2000), o espaço urbano é um conjunto de processos ecológicos associado à densidade populacional e ao fluxo migratório, à concentração de atividades, à mobilidade e acessibilidade e à segregação suscitada pelo capitalismo que promove a dinâmica urbana. A interação entre esses elementos produz a complexidade da qual se refere Castells (2005), quando acena que o ambiente construído é herança de estruturas socioespaciais anteriores e que o fluxo social determina a forma e o período da organização social. Assim, o espaço urbano se configura e se reconfigura continuamente, as práticas capitalistas são nutridas e sustentam a perpetuação de políticas excludentes.

Lefebvre (1968) também discute esse espaço. Porém, diferencia a cidade do urbano mesmo compreendendo que são indissociáveis. Para esse autor, a cidade é obra, a qual denomina de morfologia material. Acrescenta, também, que é dinamizada pela produção e pelas relações sociais e, que por essa razão, a cidade tem uma história e é movida pelo processo histórico. Essas relações é que compõem o urbano que ele chama de morfologia social, pois são relações a serem concebidas, construídas e reconstruídas pelo pensamento, engendrando um fluxo social do qual a cidade se descola. Situa, ainda, as formas de ocupação e a dinâmica urbana que conduzem o núcleo urbano, por vezes, a condições inóspitas, insalubres, apodrecendo-o ou até mesmo rechaçando-o.

Concordando com esses autores depreende-se que há impactos por diferentes usos e relações sociais. Assim, o processo de reconfiguração espacial está relacionado à ação dos agentes sociais, pelo intenso uso do solo, muito comum em cidades próximas de grandes empreendimentos privados, como no caso da cidade investigada, ampliando os conflitos socioambientais.

\section{Empreendimentos Privados, Meio Ambiente e Conflitos Ambientais}

Os conflitos socioambientais não são recentes e estão, fortemente, atrelados a condicionantes econômicos. Para Acselrad (2004), a política desenvolvimentista que estimula a instalação de grandes empreendimentos privados é muito presente na realidade amazônica. Essa política desenvolvimentista se desdobra no estado de degradação do espaço urbano que o autor chama de meio ambiente. Para esse autor o adensamento populacional se materializa no 
entorno desses empreendimentos que, por vezes, instalam-se em locais que não têm capacidade para abarcar o fluxo populacional atraído dos mais variados lugares, ampliando os problemas e os conflitos socioambientais.

Ainda nessa direção, Acselrad (2004) assinala que estudar os conflitos ambientais significa uma tentativa de dar visibilidade aos distintos atores sociais, ampliando-se o debate sobre infraestruturas urbanas. $\mathrm{O}$ autor considera que não é possível segregar a sociedade do meio ambiente, na medida em que o ambiente se constitui de objetos com traços culturais e históricos, fundamentados pela intrínseca presença humana. Para Acselrad (2004, pp. 7-8), “[...] todos os objetos do ambiente, todas as práticas sociais desenvolvidas nos territórios e todos os usos e sentidos atribuídos ao meio interagem e conectam-se materialmente e socialmente seja através das águas, do solo ou da atmosfera".

Reigota (2004), seguindo nessa mesma linha de pensamento, alerta para o real sentido de meio ambiente, salientando que envolve múltiplas formas de vidas e relações, as quais se entrelaçam às problemáticas socioambientais. As relações dinâmicas citadas pelo autor implicam constante mutação, resultante da dialética das relações entre grupos sociais e o meio natural e construído, desencadeando processo de criação permanente, que estabelece e caracteriza culturas em tempo e espaços específicos. Essa forma de entender o meio ambiente é ratificada por Carvalho (2008) que argumenta que não se separa ambiente natural do ambiente social, ou seja, sociedade e meio ambiente estão entrelaçados, não sendo possível tratá-los de forma segregada um do outro. Assim também defende Acselard (2004).

Acselrad (2004) acrescenta, também, que a questão ambiental é intrinsecamente conflitiva, porém nem sempre considerada nos debates públicos. Afirma que os conflitos decorrem de injustiça social e distorções de natureza econômica, sendo o uso do solo um dos principais indutores desse processo com múltiplos desdobramentos, especialmente relativo à ocupação irregular, que envolve múltiplas formas de vida e relações as quais se entrelaçam às problemáticas socioambientais (Reigota, 2004).

\section{Educação Popular}

Na compreensão sobre educação popular Loureiro e Franco (2014) referenciam que emerge a necessidade dos que vivem na condição de oprimidos e expropriados dialogarem, construindo alternativas, coletivamente, para solução de seus problemas. 
Segundo Freire (2011) trata-se de uma educação política, libertadora, que implica constante desvelamento da realidade. Amplia o olhar crítico, liberta, estimula a criatividade e a reflexão sobre a realidade. Ancora-se na historicidade dos homens, razão pela qual está sempre em construção. Sobre esse prisma, os homens são considerados seres inconclusos, inacabados. "Para a educação problematizadora, enquanto um 'que fazer' humanista e libertador, o importante está em que os homens submetidos à dominação lutem por sua emancipação" (Freire, 2011, p.105).

Wanderley (2010) também manifestou contribuições sobre a educação popular quando descreve algumas características. Para ele, trata-se de uma educação que exige consciência dos interesses das classes populares; considera-se histórica, pois se vincula ao avanço das forças produtivas; tem um caráter político, social, transformador, libertador e democrático. $\mathrm{O}$ autor destaca que por meio da educação popular vislumbram-se mudanças qualitativas, ações antiautoritárias, antimassificadoras, antielitistas, além de associar a teoria com a prática e a educação com o trabalho.

De acordo com Wanderley (2010), Freire serviu de inspiração para reflexões e construções de outros autores sobre a educação. E, ainda nos dias atuais, suas ideias inspiram aqueles que vislumbram transformações, liberdade de decisão, criatividade na educação e suas práticas pedagógicas, na educação formal, como também, no seio da sociedade. Assim, a educação popular pode ser desenvolvida em comunidades e nos múltiplos espaços informais. A ideia é proporcionar ao povo fatores de motivação que os instigassem a tomar consciência de si mesmo e, por iniciativa própria, possam crescer, galgando espaço em todos os níveis, descobrindo seus próprios valores e aprendendo a lutar por seus direitos.

Para Freire (2011, p. 81), “[...] só existe saber na invenção, na reinvenção, na busca inquieta, impaciente, permanente, que os homens fazem do mundo, com o mundo e com os outros". Segundo esse autor (1967, p. 106), é indispensável para a organização reflexiva, "educação que lhe pusesse à disposição, meios com os quais fosse capaz de superar a captação mágica ou ingênua de sua realidade, por uma dominantemente crítica". Na sua visão, a consciência crítica refere-se à representação das coisas e dos fatos como empiricamente ocorrem no cotidiano, no entanto, são necessários meios que possibilitem autonomia aos sujeitos, considerando a sua condição de detentores de direitos e não apenas de deveres, os quais também são autores de sua trajetória de vida.

Revista de Gestão e Secretariado-GeSec, São Paulo, v. 7, n. 2, p 80-103,mai./ago. 2016. 
Sob essa base, compreende-se a educação popular como uma proposta de educação que se opõe à cegueira que em geral permeia os processos educativos, quando não são projetados numa perspectiva integradora e dialógica, que desconsidere os saberes formulados e produzidos no cotidiano. A educação popular, portanto, pode ser entendida também, como uma educação política porque prioriza as classes menos favorecidas, as populações que vivem em situação de risco iminente e de vulnerabilidade social.

A palavra dialogicidade embora seja materializada pela ação, sem a reflexão se converte apenas em ativismo, ação pela ação. A existência humana "[...] não pode ser muda, silenciosa, nem tampouco pode nutrir-se de falsas palavras, mas de palavras verdadeiras, com que os homens transformam o mundo (Freire, 2011, p. 108)". Freire adverte que a palavra é direito de todos e por essa razão não deve ser dominada por poucos.

Sobre esse prisma, Esteban (2007, p.15) se manifesta expressando que, os diálogos favorecem a construção de projetos coletivos a partir das experiências dos sujeitos e das classes populares e que possam ser interpretados como possibilidades de inserção nas práticas pedagógicas captadas no seio das comunidades. Na sua concepção, a produção do conhecimento ocorre de forma relacional. Assim, instigar o olhar crítico da sociedade é fundamental e a educação popular pode ser uma das alternativas contributivas nesse processo e no acesso ao imaginário social conforme defende Laplantine e Trindade (2003).

\section{Círculo de Cultura, Imagem e Educação Ambiental}

O Círculo de Cultura (Freire, 2011) consiste na estimulação de debates em grupos. Um dos princípios é a participação livre e crítica e tem por objetivo oportunizar os debates por meio do uso de imagens da realidade vivida pelos participantes. Durante os debates, utilizavam-se fotografias como código da situação existencial dos participantes a fim de torná-la concreta. Tal recurso possibilitava reflexões concomitantes e críticas sobre a imagem projetada que foi denominada de decodificação. Ao encontro desse pensar, Martins (2014) anuncia que "[...] a fotografia muito acrescenta na medida em que permite ver o que por outros meios não pode ser visto". Há nessa proposta uma frutífera oportunidade de intercâmbio na produção do conhecimento sobre a realidade.

O Círculo de Cultura tem enfoque epistemológico e metodológico (Loureiro \& Franco, 2014) e como proposta metodológica, a partir da apropriação de denominações e 
intensidades diferentes, pode ser adotado como alternativa para se trabalhar a educação ambiental em espaços formais e não formais. A expressão educação ambiental surgiu num encontro de educadores que houve em 1965, em Keele, na Inglaterra. Mas a sua evolução foi discutida na Conferência de Educação Ambiental de Tbilisi, no sentido de que deveria alcançar todos os âmbitos tanto na educação formal quanto não formal e que tal educação deveria ser orientada para a comunidade, num reconhecimento de interdependência existente entre o ambiente natural e o construído. Jacobi (2003, p. 193) sustenta que "[...] a educação ambiental é condição necessária para modificar um quadro de crescente degradação socioambiental [...]", embora não seja suficiente. Trata-se de uma ferramenta mediadora entre distintas culturas, comportamentos e interesses coletivos para a transformação desejada.

\section{CAMINHOS METODOLÓGICOS DA PESQUISA}

As circunstâncias socioambientais urbanas vivenciadas pelos moradores de Laranjal do Jari foram inspiradoras da pesquisa realizada, que se desenvolveu no ambiente urbano, o qual coaduna história, dinâmicas socioespaciais, conflitos e contradições. Para melhor definição das práticas pedagógicas utilizadas nas atividades de campo apoiou-se no método histórico e dialético.

O método histórico é relevante na compreensão do espaço urbano porque busca desvelar suas "[...] transformações, recuperando informações sobre sua evolução, sua decadência, sua crise, suas limitações, suas formas de divulgação, sua aceitação pela comunidade científica etc.” (Gamboa, 2007, p. 57). Nessa linha, Pérez et al. (1996) advogam que por meio do método histórico será possível estudar a trajetória dos fenômenos e dos fatos no decorrer da sua história, que foram indutores de uma dada realidade, numa interação entre o passado e o presente. Os autores advertem que esse método objetiva reconstruir e elucidar a inter-relação que permeia narrativa, tempo e ação em que se insere o contexto analisado. Em relação ao método dialético apropriou-se da concepção de Gil (2008) quando afirma que as ideias se sobrepõem à matéria, ou seja, as contradições se transcendem e originam novas contradições que passam a requerer soluções.

Delineou-se a pesquisa pela abordagem qualitativa (Bogdan \& Biklen, 1994), e o tratamento dos dados norteou-se pela análise de conteúdo (Bardin, 2010). As estratégias de pesquisa foram pensadas e definidas com base na concepção dialógica de Freire (1979), que

Revista de Gestão e Secretariado-GeSec, São Paulo, v. 7, n. 2, p 80-103,mai./ago. 2016. 
prescreve ser necessária uma educação que possibilite ao homem discutir, corajosamente, a problemática, na qual se insere. Os protagonistas da pesquisa, 48 pessoas identificadas com três letras maiúsculas, são moradores de cinco bairros situados na área urbana da cidade, possuindo idade que variavam entre 18 e 65 anos, com distintos níveis de escolarização e atuantes em diferenciadas profissões. Para seleção dos bairros o critério foi a localização, a densidade populacional e a semelhança em relação às questões socioambientais.

O diálogo com os sujeitos foi modelado no "Círculo de Cultura" (Freire, 1967), em rodas de conversa que prevê a participação livre e voluntária em debates, sem limite do número de participantes nas atividades que foram propostas. Por essa razão não houve definição prévia do número de participantes, interposição de condições para participação da pesquisa, nem critério de seleção dos participantes. Assim, adotou-se a técnica de amostragem do tipo "acessibilidade ou por conveniência" (Gil, 2008, p. 94), a qual segundo esse autor é aplicável em estudos de caráter qualitativo e requer menos rigor que os demais tipos. Vale ressaltar, que os 48 sujeitos mencionados foram os que compareceram aos debates. Quando se pensa em trabalhar com educação popular [...] o Círculo de Cultura, geralmente aparece como fonte primária de inspiração para efetivar ações coletivas dialógicas e de prover comunicação entre diversos sujeitos (Loureiro \& Franco, 2014).

Como recurso metodológico utilizaram-se imagens fotográficas para a concretude de problemas cotidianos enfrentados pelos participantes da pesquisa. Foram utilizadas imagens aéreas da cidade produzidas por outros pesquisadores e imagens produzidas pela própria pesquisadora, que fotografou as más condições socioambientais visíveis em toda a cidade, para verificar a reação dos participantes ao se depararem com a realidade.

Essas imagens foram projetadas nas rodas de conversa, para instigar o debate no encontro dialógico com os sujeitos, possibilitando captar nas falas o significado acumulado no imaginário coletivo, acerca das questões socioambientais em análise e extrair de suas falas possibilidades para minorá-las. Para Laplantine e Trindade (2003, p. 25) “o imaginário representa a tradução mental de uma realidade exterior percebida". Do cotidiano vivenciado extraem-se imagens, que ao serem apresentadas aos moradores provocaram variadas sensações, que permitiram depreender como usam os significados para expressarem seu entendimento da vida real.

As rodas de conversa (Freire, 1967) constituem uma forma apropriada aos processos de leitura e intervenção comunitária. Consistem em um método de participação 
coletiva e tendem a estimular os sujeitos à reflexão crítica sobre a imagem projetada, favorecendo a construção da autonomia e o exercício da cidadania. Considerando que a comunidade reúne pessoas com distintos níveis de escolarização, o uso de imagens foi um elo de integração para que os sujeitos pudessem participar ativamente dos debates, expressando o que pensam sobre a realidade em que vivem, sendo esse um dos pressupostos da educação popular.

A educação popular, para Wanderley (2010), tem um caráter social, transformador, libertador e democrático, pode ser desenvolvida nas comunidades e, em múltiplos espaços informais, ultrapassando os limites das escolas, carecendo não apenas atingir crianças e jovens, mas toda a população e vários espaços extraescolares. Esteban (2007, p. 11), por seu turno, entende que essa forma de educação destina-se a alcançar pessoas que compõem um segmento que foi “[...] historicamente negado, marginalizado, abandonado, fracassado". Com tal perspectiva utilizou-se esse recurso como instigador nas reflexões sobre o ambiente de vivência dos participantes.

\section{A PERCEPÇÃO DOS MORADORES SOBRE AS QUESTÕES SOCIOAMBIENTAIS LOCAIS: ALGUNS RESULTADOS}

A cidade em análise está assentada na menor parcela territorial do município (menos de 1\%), mas absorve 94,9\% da população, grande parte das demandas por serviços e equipamentos públicos, além de acumular todas as questões que afetam as cidades de um modo geral (Paixão 2008). As áreas protegidas e de uso privado somam mais de $99 \%$ das terras do município. Quando se coteja a atenção a essas áreas por parte das instâncias governamentais, com a que se destina à cidade de Laranjal do Jari, observa-se uma irrefutável contradição, na medida em que às áreas protegidas dedica-se atenção diferenciada em detrimento ao caos da cidade.

É, substancialmente, válida a preocupação, por parte das instâncias de governo, com a preservação de áreas naturais sem ou com pouca intervenção humana, considerando os benefícios à vida em todas as suas faces. Contudo, entende-se que o poder público também deveria dedicar atenção, o mínimo existencial, à cidade em referência que se encontra sem nenhum trato socioambiental. No meio ambiente não se pode dissociar o natural do social (Reigota, 2004; Acselrad, 2004; Carvalho, 2008), desse modo, os problemas afetam concomitantemente os dois segmentos. $\mathrm{O}$ ambiente de vivência dos moradores ratifica essa

Revista de Gestão e Secretariado-GeSec, São Paulo, v. 7, n. 2, p 80-103,mai./ago. 2016. 
afirmação, pois revela uma feição de pobreza predominantemente urbana e que denota a precarização da vida em sociedade. Revela, ainda, a situação de risco ambiental que submete a população local à condição de vulnerabilidade onde as possibilidades de sobrevivência representam a marca da desigualdade social impregnada na cidade.

No caso de Laranjal do Jari as ocupações urbanas são densamente antropizadas e se assentam, sobretudo, em áreas de várzea, engendrando uma questão ambiental permeada de conflitos nos moldes defendidos por Acselrad (2004). As pessoas constroem suas moradias da forma que suas possibilidades financeiras permitem e, pelas condições do solo, a degradação ambiental é inevitável. As ocupações improvisadas e os problemas socioambientais mantêmse como se não pudessem ser descolados da morfologia urbana.

Lefebvre (1968, pp. 46-47) assinala que “[...] a cidade tem uma história; ela é obra de uma história, isto é, de pessoas e de grupos bem determinados que realizam essa obra em condições históricas". Isto é, a cidade não funciona sem o fluxo social e nem este sem a cidade. São indissociáveis, imbricados numa relação de interdependência que se reformula ao longo do tempo, engendrando transformações. Esse posicionamento coincide com o pensamento de Castells (2000) acerca da constituição do espaço urbano e sua complexidade, o autor também defende que a tessitura desse espaço é produto de um conjunto de processos ecológicos movidos pelas relações sociais que se estabelecem.

Na cidade de Laranjal do Jari essa relação elucida o caos socioambiental que se alinhava por décadas. A cidade cresce em direção às áreas de terra firme, e em meio a esse processo as questões socioambientais se alastram para as áreas expandidas, não contribuindo para que ela cumpra a sua função social. As circunstâncias socioambientais assinaladas indicam que há subtração do direito à cidade, segundo a concepção de Lefebvre (1968, p. 135) ao destacar o "direito à liberdade, à individualização na socialização, ao habitat e ao habitar".

Durante a realização da pesquisa os participantes apontaram diversos problemas, assim como as possíveis soluções, dentre os quais extraíram-se os que estão sintetizados no Quadro 1 e que a seguir serão descritos e analisados à luz do referencial utilizado. As expressões faciais e as falas pareciam anunciar que estar diante de imagens do seu contexto de vivência e debatendo entre si a própria realidade inspirados no sentimento de pertencimento, significava a oportunidade de se depararem com um cenário concreto, mas não visto cotidianamente com o mesmo olhar.

Revista de Gestão e Secretariado-GeSec, São Paulo, v. 7, n. 2, p 80-103,maio./ago. 2016. 
Quadro 1 - Alguns problemas e soluções apontados pelos moradores participantes da pesquisa.

\begin{tabular}{|c|c|}
\hline Problemas & Soluções \\
\hline $\begin{array}{l}\text { Acúmulo de lixo e ausência de coleta em passarelas de } \\
\text { madeira. }\end{array}$ & $\begin{array}{l}\text { Construção de carros coletores de lixo apropriados para } \\
\text { trafegar nas passarelas de madeira. }\end{array}$ \\
\hline Lixão a céu aberto. & Construção de aterro sanitário (Lei 12.305/210). \\
\hline $\begin{array}{l}\text { Ausência de fossas para depósito de dejetos humanos, } \\
\text { induzindo o lançamento direto no rio que abastece a } \\
\text { cidade de água para uso doméstico. }\end{array}$ & $\begin{array}{l}\text { Confecção de biodigestores para transformação dos } \\
\text { dejetos humanos em gás metano. }\end{array}$ \\
\hline Espaço urbano desordenado, antropizado e insalubre. & \multirow{4}{*}{$\begin{array}{l}\text { Criação de cooperativa; } \\
\text { Realização de cursos sobre reutilização e reciclagem de } \\
\text { resíduos; } \\
\text { Promoção de Educação ambiental compartilhada entre os } \\
\text { moradores; } \\
\text { Inserção da Educação Ambiental na Educação Formal } \\
\text { como disciplina; Introdução nos currículos escolares de } \\
\text { atividades para realização de análise qualitativa da água; } \\
\text { Conscientização. }\end{array}$} \\
\hline Acúmulo de resíduos sólidos e de madeira. & \\
\hline Coleta irregular de lixo em área de terra firme. & \\
\hline $\begin{array}{l}\text { Inexistência de coleta seletiva. } \\
\text { Utilização inadequada de recipiente para armazenamento } \\
\text { de água pelos moradores. }\end{array}$ & \\
\hline $\begin{array}{l}\text { Água para consumo contaminada e esgoto a céu aberto. } \\
\text { Ausência de apoio do poder público e de organizaçôes } \\
\text { sócias para mitigar os problemas. }\end{array}$ & $\begin{array}{l}\text { Atuação do poder público para que a cidade cumpra, de } \\
\text { fato, a sua função social. }\end{array}$ \\
\hline
\end{tabular}

Fonte: Acervo próprio, 2013.

A precária tessitura da cidade de Laranjal do Jari e suas implicações no cotidiano da população local são inquietantes quando se cotejam: a produção de lucros pela exploração de riquezas naturais e a pobreza da população aliada ao incipiente acesso aos equipamentos e serviços públicos; a proteção de áreas municipais e o caos da cidade; o avanço capitalista e a luta pela sobrevivência.

Ao projetar a imagem aérea da cidade, o impacto foi imediato e suscitou reação dos moradores participantes da pesquisa. As falas expressaram a configuração da cidade contida no imaginário coletivo. Alguns disseram: “olha, tem a forma de uma âncora! Parece uma espinha de peixe!" O olhar era de deslumbramento e de espanto. Essa reação reforça o posicionamento de Martins (2014, p. 33) quando afirma que a fotografia "[...] é a forma peculiar de expressão do imaginário social e da conveniência social”. Na sequência, perguntou-se: quando vocês olham essa imagem e se sentindo moradores, o que vem à mente? As respostas foram surpreendentes:

Laranjal parece uma árvore de cascalho, uma árvore seca, desmatada, uma favela; parece um garimpo; parece a Serra Pelada; lixeira. Quando se fala em Laranjal do Jari a gente pensa que é uma maravilha,

Revista de Gestão e Secretariado-GeSec, São Paulo, v. 7, n. 2, p 80-103,mai./ago. 2016. 
só a gente vindo pra ver o que é né, vou chegar e ver uma lixeira; ver que não é lá essas coisas; incêndios; enchentes.

A “[...] a fotografia pode contribuir significativamente para desvendar aspectos do imaginário social e das mediações nas relações sociais” (Martins, 2014, p. 36). Observou-se que a maioria dos participantes associou a cidade com uma favela, numa situação excludente socialmente e precária em sua estrutura urbana. De fato, as ocupações irregulares foram densamente assentadas em áreas de várzea, modelando uma enorme favela fluvial, porém as mazelas socioambientais se avolumaram e se espraiaram por toda a cidade. A relação de convivência dos moradores locais com a insalubridade é concreta e alguns aspectos passam despercebidos ou são assimilados como parte do cotidiano, por isso não são vistos. Esse é o caso dos animais roedores e insetos sob as moradias e entorno que não foram mencionados nas falas.

Nesse contexto, o risco da proliferação de doenças, ocorrência de incêndios, enchentes, multiplicação de roedores, insetos, dentre outros vetores de doenças das mais variadas espécies, é iminente. "Assim se entrevê, através dos problemas distintos e do conjunto problemático, a crise da cidade. [...]. Na prática o núcleo urbano está rechaçando, [...]; frequentemente deteriorado, às vezes apodrecendo, [...]" (Lefebvre, 1968, p. 13). A degradação e as vulnerabilidades socioambientais somam-se a um processo perverso de fabricação de pobreza, nutrido por relações de poder que naturalizam as condições mínimas de sobrevivência como suficientes para qualidade de vida.

Sobre a contaminação da água do rio, assim falou STA: "o meu marido uma vez foi tomar banho, ele mergulhou, quando ele buiou, o cabelo do marinheiro, o troféu, veio na cabeça dele" (risos). Nessa fala há palavras que são peculiares na forma de expressão amazônica. Para esse sujeito "buiou" significa emergir e "cabelo do marinheiro, troféu" refere-se a fezes. Esse fato não é incomum diante do desprovimento de condições sanitárias salubres.

Em relação ao lixo, as inquietações foram evidentes, visto que, segundo eles, o atendimento à população é incipiente e inadequado. $\mathrm{O}$ acúmulo de lixo e de esgoto a céu aberto surpreende visitantes e os interessados em morar em Laranjal do Jari. De acordo com $\mathrm{SAB}$ "nas passarelas não tem coleta de lixo, até as fossas, os dejetos humanos são lançados direto no rio, e essa água também pode estar contaminada”. Sobre esse aspecto ROC afirmou: “às vezes a gente coloca o lixo na lixeira, mas passa de dois a três dias lá. E muitas vezes eles 
jogam na caçamba e cai até fora do outro lado do carro e fica lá. Aí vem cachorro, vem urubu, vem gato, vem tudo aí fazer aquela poluição".

Ainda que haja coleta regular e em veículos adequados não há local apropriado para depósito. Há um lixão a céu aberto, distante $6 \mathrm{~km}$ do perímetro urbano (Paixão, 2008). A Política Nacional de Resíduos Sólidos (Lei no 12.305/2010) estabeleceu como uma das metas a serem cumpridas pelos municípios brasileiros até o dia 2 de agosto de 2014 (Brasil, 2010), a eliminação de lixões e a construção de aterros sanitários para depósito de rejeitos. Laranjal do Jari ainda infringe essa determinação, pois não há nenhuma perspectiva de providência nesse sentido.

No que concerne ao sistema de fornecimento de água tratada foram manifestadas algumas angústias. SAB assinalou que: “com relação à água, no ano passado eu fiz um trabalho sobre o pH e a água aqui é um pouco ácida, a qualidade está comprometida". MOR mencionou que em razão do incipiente fornecimento de água, para armazenagem, "a maioria das pessoas usa tambores de ferro, de plástico sem tampa", por não disporem de outros recipientes.

A Pesquisa Nacional de Saneamento Básico (PNSB), realizada pelo IBGE em 2008, trouxe revelações que corroboram com o que disseram os moradores. Sobre esgoto sanitário e o sistema de drenagem urbana, constatou que o município de Laranjal do Jari é desprovido da prestação desses serviços. No que diz respeito ao abastecimento de água, apontou que é atendido por rede de distribuição, mas a qualidade está comprometida. O tratamento foi considerado parcial, somente para desinfecção. Quanto à coleta de lixo é importante frisar que há a coleta domiciliar, porém, de acordo com IBGE (2008), a coleta seletiva não existe, nem no âmbito do estado do Amapá. Não há, também, destinação de recursos para essa finalidade.

Sobre resíduos sólidos, segundo MAR, descarta-se cubas utilizadas para embalagem de ovos e sacos plásticos, que levam anos para decomposição. Nessa mesma linha, MOR (doméstica) ressalta: “O que a gente mais vê é garrafas PET, plástico, é complicado. A gente não sabe aproveitar, porque não sabe fazer nada." O mesmo ocorre com os resíduos de madeira que são descartados pelas serrarias e estragam por não terem uma destinação útil, quando poderiam ser aproveitados. Uma das alternativas sugerida, pelos participantes da pesquisa para aproveitamento de resíduos sólidos, inclusive derivados da madeira, diz respeito à constituição de uma cooperativa. De acordo com MAR: 
A comunidade tem que montar uma cooperativa. A gente chama alguém pra dar um curso, pra aproveitar e talvez até ganhar um dinheirinho, angariar recurso pra comunidade, construir passarela. Para isso acho que tem que existir a cooperativa. Só que é difícil, a gente convida pra reunião, pra palestra, essas coisas, e eles não vêm.

Segundo a Organização das Cooperativas Brasileiras o cooperativismo é um importante gerador de renda e inserção social a um número cada vez maior de pessoas. Dessa forma, comunidades poderão se tornar autônomas financeiramente e não reféns das políticas assistencialistas. Legitimamente, a Política Nacional de Cooperativismo surge no Brasil com a sanção da Lei 5.764/71 (Brasil, 1971). De acordo com essa lei (Arts. $3^{\circ}$ e $4^{\circ}$ ) as cooperativas são sociedades de pessoas, constituídas para prestar serviços aos associados que, reciprocamente, obrigam-se a contribuir com bens ou serviços para o exercício de uma atividade econômica, de proveito comum, sem objetivo de lucro.

Assim, advoga-se que a constituição de cooperativas deveria ser estimulada pelo poder público e organizações sociais, posto que, tende a fortalecer o associativismo, revelar a capacidade empreendedora de seus integrantes, induzir a confiança mútua e o espírito da reciprocidade entre os cooperados, os quais são requisitos fundamentais nesse processo, além do engajamento político dos integrantes. A fala de MAR revela o esforço em concretizar essa proposta, diante de tanta matéria-prima, porém, evidencia essa necessidade de apoio de entidades de classe e poder público no convencimento à população local de que se trata de uma alternativa benéfica aos seus integrantes.

Doravante, descrevem-se alguns resultados da pesquisa que enfocam a importância da Educação Ambiental para mitigação dos problemas apontados. Sobre a abordagem dessa temática na escola VAS disse que "não se deve tratá-la de forma setorizada na Escola, no conforto da sala de aula climatizada, e sim de forma ampliada, integrando ao currículo e com envolvimento de toda a escola". Em relação à introdução no currículo escolar como disciplina, a fala de JES também seguiu nessa direção, mas defendeu a integração ao currículo desde a Educação Infantil, justificando que as crianças são capazes de influenciar seus pais e assim se expressou: “a Educação Ambiental deveria ser feita desde o pré-escolar. Deveria existir essa disciplina de Educação Ambiental nas escolas, porque só dão Educação Ambiental de $5^{\text {a a }} 8^{\text {a }}$ série. ROS, também assinalou que a Educação Ambiental "seja uma matéria obrigatória nas escolas, ensinar desde o jardim, o maternal, a criança cresce com aquilo na mente".

Outros participantes seguiram na mesma linha de raciocínio. Posicionamentos 
como esses contrastam com os Parâmetros Curriculares Nacionais (Brasil, 1997) e a Lei n. 9.795, de 27 de abril de 1999, os quais prescrevem que a Educação Ambiental deve ser incorporada ao currículo como tema transversal, ou seja, perpassando por todas as disciplinas dos currículos relativos à Educação Básica, sem indicativo de criação de uma disciplina específica. Vale destacar que a visão dos participantes convergiu para uma educação assentada na perspectiva defendida por Loureiro e Franco (2014, p. 174), ou seja, tomando-se como suporte os princípios delineados pelo Círculo de Cultura na proposição de:

Uma prática pedagógica revolucionária, em que a diretividade do processo converge para o desvelamento das intencionalidades atribuídas ao saber na problematização de suas finalidades (onde, quando e como são utilizados e satisfazendo a que interesses) por intermédio da ação dialógica permanente.

Veiga-Neto (2002, p. 156) argumenta que "os temas transversais, funcionando como um caminho epistemológico que corta variadas regiões dos saberes podem estar instituindo o entendimento de que tudo é (naturalmente) possível e recorrível a qualquer momento." Acrescenta, também, que esses temas podem estar atrelados a práticas de dominação e importação de traços culturais que, estranhamente, se incorporam à mobilidade entre diversos campos do saber, sem associação com a realidade em que se desenvolvem. Distorções como essas não contribuem para minoração dos perversos efeitos causados ao meio ambiente, como os que existem em Laranjal do Jari.

Essas manifestações sugerem que no currículo sejam previstas práticas de testes relativos às condições da água que serve para usufruto da população e devem apontar as consequências da utilização inadequada de recipientes para armazenagem da água para uso doméstico. Ademais, indicaram a urgência de previsão de atividades dirigidas à reciclagem ou reutilização de resíduos, sendo uma delas a constituição de cooperativas, que também podem gerar recursos para aplicação na própria comunidade. Alguns participantes propuseram a confecção de biodigestores (equipamento que transforma dejetos humanos em gás metano para uso doméstico), além de um carro coletor apropriado para circular em passarelas de madeiras. Houve menções também, acerca do termo "conscientização", como um elo forte na Educação Ambiental, porém com o sentido de sensibilizar, de que a pessoa sabe o que é correto, mas pratica o incorreto, e não com "o olhar mais crítico possível da realidade." (Freire, 1979, p. 17).

De acordo com Jacobi (2003) a educação ambiental deve visar o resgate da solidariedade, além da igualdade e o respeito à diferença, mediados por ações democráticas 
que estejam sustentadas por práticas interativas e dialógicas. Uma Educação Ambiental que, de fato, seja funcional e, portanto, praticável, deve ser aprofundada. Esteban (2007), por exemplo, entende que um programa de Educação Ambiental pode iniciar na educação formal, posto que buscou captar possibilidades pedagógicas no contexto social. Todavia, na educação formal existe o óbice na materialização da transversalidade num modelo curricular como o brasileiro, que é compartimentalizado em disciplinas, transferindo a todos e a ninguém a decisão e o compromisso de implementar tal princípio, que no nosso entendimento pode ser utilizado em favor da Educação Ambiental, desde que o corpo técnico-pedagógico e docente se organize para tanto.

Os moradores envolvidos na pesquisa também apresentaram propostas de Educação Ambiental para aplicação fora da Escola, o que já é um indício de que eles pensam uma educação que envolva a comunidade, como enfatizou BAS: "fazer um trabalho de educação corpo a corpo, no contato direto com cada morador". A Educação Ambiental referida por BAS está associada à tradição da Educação Popular (Freire 1967; 1979; 2011; Wanderlei, 2010), que compreende o processo educativo como um ato político no sentido amplo, isto é, como prática social que conduz o sujeito ao exercício da cidadania, o que não descarta a participação da escola. Nessa perspectiva, a proposta de Educação Ambiental popular deve coincidir com a vocação da educação para formação de sujeitos que, inseridos numa conjuntura sociopolítica, se tornem capazes de agir criticamente na sociedade (Freire, 1967).

No entendimento de Carvalho (2008, p. 26), as práticas de Educação Ambiental urbana, como meio de inserção dessa temática no contexto coletivo de forma compartilhada e democraticamente negociada, devem contemplar as seguintes modalidades de ações desde que repensadas e ajustadas à realidade local:

[...] organização de reuniões nas diferentes associações de bairros mobilizadas para a temática socioambiental, onde poderão ocorrer apresentações, mostras de vídeos, fotografias, cartazes e palestras para esclarecer o debate sobre um ou mais temas de interesse local; a promoção de cursos, seminários, oficinas e, principalmente, debates [...].

A pesquisa seguiu nessas trilhas, tendo em vista que, apoiadas em Freire (1967), acreditava-se que as discussões em grupo e o uso de imagens sobre a realidade seriam inspiradores para problematização de questões cotidianas, sobretudo as de natureza socioambientais. Nessa perspectiva sobressai o entendimento de Castells (2005) acerca do 
ambiente como um sistema complexo de relações e interações da base natural com o social, tendo por arcabouço a forma de apropriação pelos diversos grupos, populações e interesses sociais, políticos e culturais que nesse contexto se fundam, perpetuando práticas capitalistas que patrocinam políticas de exclusão social.

As concepções ora discutidas sinalizam que a incursão da Educação Ambiental na Educação Formal, como disciplina, e numa direção voltada para a transformação socioambiental ainda é remota, bem como as práticas pedagógicas do modelo educacional vigente não promovem o equacionamento das questões socioambientais em destaque. Contudo, entende-se que a Educação Ambiental deve ter por arcabouço a forma de apropriação pelos diversos grupos, populações e interesses sociais, políticos e culturais para não se tornar, simplesmente, bandeira política ou configurada em "projeto de gaveta", sem efetividade na minoração dos problemas socioambientais postos em uma determinada realidade.

O debate em grupo, reforçado com a projeção de imagens da realidade de moradores, ratificou a compreensão de que o saber e o fazer em Educação Ambiental exige o envolvimento de todos os segmentos sociais. Isso ficou evidente nos significados contidos no imaginário individual e coletivo, manifestados por eles, carregado de sensações e emoções que estão referenciadas nas vivências concretas (Laplantine \& Trindade, 2003). Essas sensações coletivas, por vezes ofuscadas pelo fluxo da vida cotidiana, podem sugerir relevantes temas para uma proposta curricular de formação em Educação Ambiental, em consonância com a realidade analisada, em que se busca superar a maneira como são assimilados os processos individuais e coletivos de aprendizagem. Para melhor compreender o que pensam os sujeitos, o diálogo foi fundamental, pois são eles que vivem nas periferias sociais (Esteban, 2007). As falas dos moradores sinalizaram, sobretudo, para o desejo de mudança, diante das imagens projetadas e das circunstâncias socioambientais postas.

\section{CONSIDERAÇÕES FINAIS}

Quando se analisa a situação urbana da cidade de Laranjal do Jari, cuja desorganização socioespacial é peculiar de cidades que se formam nas periferias de grandes empreendimentos econômicos, observa-se que os conflitos e as contradições fortalecem a 
ideia da urgência no envolvimento da sociedade em discussões que permeiam as questões cotidianas.

As questões socioambientais são visíveis em Laranjal do Jari e se tornaram parte da vida cotidiana dos moradores sem que estes tenham o entendimento do seu direito em intervir para equacioná-las, mitigá-las ou evitá-las. O impulso nesse sentido deve partir de cada um dos moradores e deles em conjunto, pois o espaço urbano é constituído pela dinâmica das relações sociais que lá se estabelecem. É evidente que essas relações são conflituosas, mas, no contexto arrolado, há também um processo de aprendizagem acerca do ambiente de vivência, que se revelou na pesquisa realizada, tendo em vista que, os moradores expuseram o que pensam para mitigar o quadro em análise. Entretanto, é urgente que haja um olhar prioritário, pois não se pode admitir que tantas questões dessa natureza avolumem-se, interfiram e, estranhamente sejam naturalizadas à vida humana.

Os resultados da pesquisa revelaram que quando se trata de propor alteração no ambiente construído é fundamental convocar quem conhece a realidade em que vive. A mobilização de moradores nas atividades desenvolvidas em campo pode tê-los inspirado a debaterem as questões postas diante das imagens projetadas. Oportunizou também o exercício da cidadania expressado no diálogo produzido por meio da linguagem popular ao privilegiar a participação como um processo político. A educação popular, enquanto educação para o povo, formulada no encontro com moradores, possibilitou o prenúncio de alternativas mais próximas possível das suas necessidades.

O conjunto de ideias foi bastante rico e propositivo. O conhecimento da realidade expresso pelos moradores locais foi claramente evidenciado nas suas falas, o que permitiu entender como eles tecem a leitura da cidade. A multiplicidade de soluções apontadas se dirigiu aos elementos que compõem o saneamento ambiental e, no calor dos debates, a educação ambiental emergiu espontaneamente como proposta de melhoria, com aplicação tanto na educação formal quanto inserida num contexto de transformação da própria sociedade.

\section{REFERÊNCIAS}

Acselrad, H. (2004). As práticas espaciais e o campo dos conflitos ambientais. In: Acselrad, Henri (Org). Conflitos ambientais no Brasil. Rio de Janeiro: Relume Dumará; Fundação Heinrich Böll. 
Bardin, L. Análise de Conteúdo. (1977). Tradução de Luis Antero Reto e Augusto Pinheiro. (2010). Lisboa-Portugal: Edições 70.

Bogdan, R. C. \& Biklen, S. K. (1994). Investigação Qualitativa em educação: uma introdução à teoria e aos métodos. (1991). Trad.: Maria João Alvarez et al. Porto: Porto Editora.

Brasil. Secretaria de Educação Fundamental (SEF) (1997). Parâmetros Curriculares Nacionais: terceiro e quarto ciclos: apresentação dos temas transversais/Secretaria de Educação Fundamental. Brasília: MEC/SEF,

Lei $n^{o} 5.764$ de 16-12-1971. Define a Política Nacional de Cooperativismo, institui o regime jurídico das sociedades cooperativas, e dá outras providências. web site. Recuperado em 20 de outubro, 2011, de http://www.planalto.gov.br/ccivil_03/leis/15764.htm.

Lei $n^{\circ} 9.795$ de 27-4-1999. Dispõe sobre a educação ambiental e institui a Política Nacional de Educação Ambiental. Web site. Recuperado em 13 de outubro, 2009, de http//: www.planalto.gov.br/ccvil_03/LEIS/L9795.

Lei $n^{\circ} 12.305$ de 2-8-2010. Institui a Política Nacional de Resíduos Sólidos; altera a Lei $\mathrm{n}^{\mathrm{0}}$ 9.605, de 12 de fevereiro de 1998; e dá outras providências. Web site. Recuperado em 13 de outubro, 2003, de http//: www.planalto.gov.br/ccvil_03/LEIS/L12305.

Decreto $n^{o} 8.281$ de 25-6-2002. Regulamenta a Lei 9.795 de 1999. Web site. Recuperado em 13 de outubro, 2009, de http//: www.planalto.gov.br/ccvil.

Carvalho, V. S. de. (2008). Educação ambiental urbana. Rio de Janeiro: Wad Ed.

Castells, M. (2000). A questão urbana. São Paulo: Paz e Terra.

Castells, M. (2005). Sociedade em Rede. Tradução de Roneide Venâncio Majer. $8^{a}$ edição. São Paulo: Paz e Terra.

Esteban, M. T. (2007). Educação Popular: desafio à democratização da escola pública. In: Cad. Cedes, Campinas, vol. 27, n.71, pp. 9-17, jan./abr.

Freire, P. (1967). Educação como prática de liberdade. Rio de Janeiro: Paz e Terra.

(1979). Conscientização: teoria e prática da libertação: uma introdução ao pensamento de Paulo Freire. Tradução de Kátia de Mello e Silva. São Paulo: Cortez \& Moraes.

(2011). Pedagogia do oprimido (50ª ed.) (1968). Rio de Janeiro: Paz e Terra.

Gamboa, S. S. (2007). Pesquisa em Educação: métodos e epistemologias. Chapecó: Argos.

Gil, A. C. (2008). Métodos e técnicas de pesquisa social (6a ed.). São Paulo: Atlas, 2008.

Revista de Gestão e Secretariado-GeSec, São Paulo, v. 7, n. 2, p 80-103,mai./ago. 2016. 
IBGE. (2003). Mapa de Pobreza e Desigualdade - Municípios Brasileiros. Web site. Recuperado em 25 de setembro, 2013, de http://cidades.ibge.gov.br/xtras/.

. (2008). Pesquisa Nacional de Saneamento Básico. Web site. Recuperado em 26 de setembro, 2013, de http://cidades.ibge.gov.br/xtras/temas.php?lang=\&codmun=.

(2010). Censo Demográfico. Web site. Recuperado em 14 de maio, 2013, de http://www.ibge.gov.br/cidadesat/xtras/.

Jacobi, P. (2003). Educação ambiental, cidadania e sustentabilidade. Cadernos de Pesquisa. São Paulo, n. 118, pp. 189-205, mar./2003. Web site. Recuperado em 10 de janeiro, 2011, de http/www.scielo.br/gpea/bub.

Laplantine, F. \& Trindade, L. (2003). O que é imaginário. São Paulo: Brasiliense (Coleção primeiros passos; 309).

Lefebvre, H. (1968). O direito à cidade. Tradução de Rubens Eduardo Farias (2006). São Paulo: Centauro.

Loureiro, C. F. B \& Franco, J. B., (2014). Aspectos teóricos e metodológicos do círculo de cultura. In: Loureiro, C. F. B \& Torres, J. R. (orgs.) (2014). Educação Ambiental: dialogando com Paulo Freire. São Paulo: Cortez.

Martins, José de Souza (2014). Sociologia da fotografia e imagem. São Paulo: Contexto.

Paixão, E. do S. de B. (2008). Plano diretor participativo: análise das contribuições e alternativas para os problemas urbanos das áreas de várzea do município de Laranjal do Jari (AP). Dissertação de mestrado em Desenvolvimento Regional, Universidade Federal do Amapá, Macapá.

Pérez et al. (1996) Los métodos teóricos de investigación. In: Idem, Metodología de la investigación educacional. Primera parte. La Habana.

Tostes, J. A. (2013). Transformações e dinâmicas urbanas ocorridas nas cidades do estado do Amapá (1950-2010). In: Porto, J. L. R \& Nascimento, D. M. (orgs). Dinâmicas periféricoestratégicas da fronteira da Amazônia setentrional: das políticas públicas e redes institucionais à integração espacial. Rio de Janeiro: Publit.

Reigota, M. (2004). Meio ambiente e representação social (6a ed.). São Paulo: Cortez.

Veiga-Neto, A. (2002). Uma Lança com duas pontas. In: Rosa, D. E. G. \& Souza, V. C. de. Políticas organizativas e curriculares, educação inclusiva e formação de professores. Rio de janeiro: DP\&A.

Wanderley, L. E. (2010). Educação popular: bases históricas e conexões contemporâneas. In: __ _ Educação Popular: metamorfoses e veredas. São Paulo: Cortez, pp.19-42. 